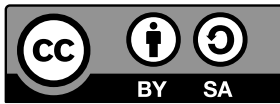

\title{
PRAKSA OCENJEVANJA ZNANJA PRI TUJEM JEZIKU STROKE V SLOVENSKEM VISOKOŠOLSKEM PROSTORU
}

Na splošno velja, da se je zanimanje za ocenjevanje znanja v terciarnem izobraževanju v zadnjih letih povečalo (Opre, 2015; Ribeiro Pereira in Assunção Flores, 2016), k čemur je zlasti prispevalo spoznanje, da ocenjevanje ne služi le podeljevanju ocen, marveč vpliva na koncipiranje pouka in ima vpliv na študentov pristop do učenja (Marentič Požarnik in Peklaj, 2002). Ribeiro Pereira in Assunção Flores (prav tam) povzemata različna razumevanja ocenjevanja in sicer

- $\quad$ ocenjevanje kot orodje za učenje

- $\quad$ ocenjevanje kot sredstvo za izboljšanje poučevanja in učenja ter

- $\quad$ na učenca osredinjeno ocenjevanje (ang. learner centred assessment)

Na pomenu pa vseeno prav nič ne izgublja ,klasični‘ pomen ocenjevanja in ocen, to je informacija, ali in v kakšni meri je študent izpolnil predpisane standarde. Ta informacija je namenjena tudi deležnikom zunaj visokošolske institucije, na primer bodočim delodajalcem ali podeljevalcem štipendij, študijskih praks in podobno. Ker se študijski uspeh študenta še vedno izraža s številčnimi ocenami in mu o(ne)mogoča prehod v višji letnik ali zaključek študija, se to odraža v prehodnosti študentov, kar je tudi eden od kazalnikov uspešnosti posamezne visokošolske ustanove. Te so vedno bolj izpostavljene mednarodnemu primerjanju, na primer v obliki akreditacij, katerih pridobitev lahko pomembno poveča ugled posamezne institucije, s tem pa tudi poveča zanimanje tako domačih kot vedno bolj tudi tujih študentov za študij na njej. Glede na vedno večjo odvisnost terciarnih ustanov od zunajproračunskih sredstev oziroma njihovo vedno večjo tržno naravnanost, je to toliko bolj pomembno.

Za ocenjevanje znanja pri tujih jezikih stroke je dolgo veljalo, da gre za malo raziskano področje, ki mu raziskovalci niso posvečali posebne pozornosti (Hutchinson in Waters, 
1987). Stanje se je začelo spreminjati šele $\mathrm{v}$ devetdesetih letih prejšnjega stoletja (Jarc in Zorko, 2014), ko je v ospredje zanimanja stopil učenec in njegove potrebe. Prve raziskave so prihajale iz ZDA in Združenega kraljestva, razumljivo so se ukvarjale z angleškim jezikom in ta primat državi ohranjata do danes, čeprav ne gre spregledati številnih raziskav z vsega sveta, precej odmevnih prihaja v zadnjem času iz Azije (npr. Chang, 2014). V Sloveniji ni veliko raziskav s tega področja, izpostavimo lahko Tratnikovo (2008), ki je pisala o ključnih zadevah pri ocenjevanju angleščine kot jezika stroke in Djurićevo (2008), ki se je ukvarjala s povratno informacijo (ang. washback) in Sejom.

Ključne teme, ki so se jim posvečali oziroma se jim posvečajo raziskovalci, izhajajo iz osnovnih posebnosti in dilem, ki spremljajo poučevanje jezika stroke, to pa so odnos oziroma interakcija med jezikovnim znanjem in znanjem stroke, vpliv nejezikovnih dejavnikov in uporaba avtentičnih oblik ocenjevanja znanja. Med novejše teme, ki zanimajo raziskovalce, lahko uvrstimo problematiko kriterijev ocenjevanja znanja (Jacoby in McNamara, 1999; Douglas, 2000, 2001), kar se je posebej izpostavilo z vključevanjem alternativnih metod ocenjevanja (Douglas, 2001; O'Sullivan, 2012), v tem kontekstu še posebej primerljivost ocen (ang. inter rater reliability). Narašča tudi število raziskav, ki obravnavajo učitelja ${ }^{1}$ tujega jezika stroke kot ocenjevalca, zlasti z ozirom na njegova prepričanja (ang. beliefs, conceptions) in njihovim vplivom na ocenjevanje znanja (npr. Chang, 2014; Zalipyatskikh, 2017). Vse bolj izpostavljena tema je tudi medkulturnost in etični vidik ocenjevanja znanja ter dostopnost testov (ang. affordability) z ekonomskega vidika, saj nekateri testi, ki so velikega pomena za testiranca (ang. high stakes tests), npr. za pridobitev državljanstva, licence za delo ipd., pomenijo zanj (pre)velik finančni zalogaj (O‘Sullivan, 2012).

Ne gre spregledati dejstva, da se večina raziskav posveča standardiziranim testom ${ }^{2}$ zlasti za angleški jezik in za specifične družbene (npr. imigranti) ali poklicne (npr. zdravniki) skupine.

Kljub opisani živahni raziskovalni dejavnosti na področju ocenjevanja znanja pri tujih jezikih stroke, to ostaja vse slej ko prej na praktični ravni, manjka pa, po mnenju vodilnih raziskovalcev (Douglas, 2000; Davies, 2001), teoretična podlaga, ki bi povezala številne prakse, o katerih pišejo posamezni avtorji oziroma zgradila most med teorijo in prakso (Brunfaut, 2014).

\subsection{Posebnosti ocenjevanja znanja pri tujih jezikih stroke v visokem šolstvu}

Ugotovitev o odsotnosti teoretične osnove še toliko bolj velja za ocenjevanje znanja pri tujih jezikih stroke na terciarni ravni, ki tako glede deležnikov kot tudi glede same prakse izvajanja odstopa od standardiziranih testov.

1 V prispevku navajamo le moške spolne oblike, kjer pa so zajeti vsi spoli.

2 V Sloveniji standardiziranih testov v visokošolskem prostoru ni (Marentič Požarnik in Peklaj, 2002). 
Glavne značilnosti ocenjevanja znanja pri tujih jezikih stroke na terciarnih izobraževalnih ustanovah lahko glede na deležnike povzamemo v naslednjem:

1) Učitelj tujega jezika stroke

Samostojnost učitelja pri ocenjevanju je pogojena z organiziranostjo znotraj posamezne ustanove: tam, kjer obstajajo tako imenovani jezikovni centri, ki pokrivajo pouk jezikov stroke na ravni na primer celotne univerze, poteka določanje vsebin in oblik ocenjevanja znanja ter tudi kriterijev zanj centralizirano ${ }^{3}$. Kjer so učitelji tujih jezikov organizirani v katedre ali njim podobne organizacijske oblike, je situacija lahko različna, lahko vsak učitelj sestavlja teste sam, ali je to skupno oziroma jih učitelji izmenjujejo. ${ }^{4}$ Neredki so primeri, kjer je za posamezen jezik na določeni instituciji zaposlen en sam učitelj, ki je povsem samostojen. Čeprav se to zdi na eni strani ugodno za učitelja, pa je večja tudi njegova odgovornost.

Poleg teh objektivnih okoliščin ocenjevanja znanja pa obstajajo tudi dejavniki, ki jih pri razmišljanju o ocenjevanju znanja na področju tujih jezikov stroke ne gre spregledati, to pa je, da učitelji tujih jezikov stroke nimajo izobrazbe v stroki, katere jezik predavajo. Skoraj vsi brez izjeme so po osnovni izobrazbi jezikoslovci in morajo svoje znanje splošnega tujega jezika sami nadgraditi z znanjem vsakokratne stroke (na primer ekonomije, strojništva, etnologije itd.). Glede na to, da strokovne vsebine in zlasti terminologija predstavljajo vsebinsko jedro pouka tujih jezikov stroke in posledično tudi ocenjevanja znanja, je torej v literaturi pogosto izpostavljeno vprašanje, ali je učitelj TJS za to sploh usposobljen (McNamara in Ryan, 2011; O‘Sullivan, 2012). Ta učiteljev specifični položaj se odraža v celotnem pedagoškem procesu in s tem tudi v ocenjevanju znanja.

\section{2) Studenti}

Ciljna skupina so študenti različnih študijskih programov. Značilno za ciljno skupino je, da je običajno heterogena glede na predznanje. Druga značilnost je, da (še) nima veliko znanja stroke, še manj pa predstave o potrebah v kasnejšem poklicu in teh potreb zato ni sposobna ubesediti. Tudi temu morda lahko pripišemo njen določen odpor do avtentičnih oblik ocenjevanja, kar je pokazala raziskava, ki smo jo opravili med študenti Ekonomske fakultete UL (Svetlin Gvardjančič, 2017). Poleg tega je ta skupina $v$ zadnjih desetih letih vedno bolj nacionalno heterogena, saj se število tujih študentov na visokošolskih ustanovah nenehno povečuje. ${ }^{5} \mathrm{Na}$ študij v Slovenijo prihajajo študenti iz različnih kulturnih okolij in z različnimi pričakovanji.

3 Kot primer navajamo nam poznano ureditev na Warschaw School of Economics. (Vir: osebni razgovori ob obisku v okviru Erasmus Teacher Mobility, 2014).

4 Primer: Ekonomska fakulteta v Ljubljani, učitelji angleškega jezika imajo enotne pisne izpite, ne pa tudi ustnih.

5 Po podatkih Statističnega urada RS je v študijskem letu 2017/2018 v Sloveniji študiralo 3420 mobilnih študentov, to so tisti, ki študirajo v Sloveniji, stalno bivališče pa imajo v tujini. Njihov delež med vsemi študenti v Sloveniji je $4,5 \%$. 
Kot izziv gre tu omeniti določanje nivojev znanja tujega jezika. Praksa namreč kaže, da kljub temu, da $90 \%$ študentov prihaja iz evropskih držav (Statistični urad RS, 2017) in kljub obstoju Skupnega evropskega jezikovnega okvira, poenotenja glede nivojev znanja ni in to, kar morda za učitelja v Sloveniji pomeni znanje na nivoju B1, ne pomeni, da ta raven velja tudi za učitelja v neki drugi državi. Je pa za ciljno skupino študenti značilno, da se vedno bolj zaveda pomena ne samo znanja tujega jezika stroke ampak tudi pomena ocene ${ }^{6}$, ki jo pridobi, saj je od tega neredko odvisna pridobitev prakse ali delovnega mesta (Svetlin Gvardjančič, prav tam; Ribeiro Pereira in Assunção Flores, 2016).

3) Visokošolska ustanova

Ker v Sloveniji pouk tujih jezikov stroke na terciarni ravni ni centraliziran v obliki jezikovnih centrov na ravni posameznih univerz, je izvedba pouka in s tem tudi ocenjevanja znanja $\mathrm{v}$ domeni vsake posamezne članice univerze. Slednja sicer s študijskim redom ${ }^{7}$ ali podobnim dokumentom določi formalni okvir za izvajanje ocenjevanja znanja, ki opredeljuje zlasti izpitni red, izvajanje izpitov, pogoje napredovanja in podobno. Podrobnejše opredelitve vsebujejo pravilniki posameznih članic, zlasti roke izpitov, ocene, število možnih kreditnih točk pri predmetu in drugo. Kolikor poznamo to področje, vodstva posameznih fakultet $\mathrm{v}$ sam način ocenjevanja znanja pri jezikih stroke ne posegajo, kar gre na eni strani pripisati zaščiti akademske svobode učiteljev pri njihovem delu, na drugi strani pa tudi nezanimanju za pogosto marginalizirane jezike stroke. Drugače je seveda v primeru pritožb študentov.

4) Delodajalci

Delodajalci kot tisti deležniki, ki so pravzaprav končni uporabniki, so po našem mnenju zagotovo spregledani kot sogovorniki na področju tujih jezikov stroke. Pričakujejo pa jezikovno kompetentnega zaposlenega in so glede tega pri odločanju o zaposlovanju odvisni od informacije o jezikovnem znanju, ki je rezultat ocenjevanja. Zato pričakujejo, da bodo ocene odražale dejansko jezikovno usposobljenost kandidata za določeno delo.

Če povzamemo, lahko rečemo, da večina študentov znanje tujega jezika stroke dejansko potrebuje oziroma ga bo potrebovala, saj se povečuje število tistih, ki bodisi študij deloma opravijo na tujih univerzah ali se nameravajo po zaključku študija zaposliti v tujini. Za takšen namen, torej za študij ali delo v tujejezičnem okolju, se povečuje potreba po primerljivosti ocen med visokošolskimi institucijami v različnih državah.

6 Tako opažamo, da vedno več študentov prihaja na zviševanje ocen, saj je študijsko povprečje pomembno za pridobivanje štipendij, nadaljevanje študija na drugi stopnji ipd. Delno pa najbrž to pripišemo tudi tako imenovani »inflaciji dobrih ocen (Zupanc in Bren, 2010).

7 Prim.: Študijski red Univerze v Ljubljani z dne 27.6.2017. 
Lahko bi rekli, da sta ocenjevanje znanja oziroma končna ocena na splošno postala pomembna za vse deležnike, kot izvajalec in odločevalec pa v terciarnih ustanovah ostaja slej ko prej eden, to je učitelj.

\section{RAZISKAVA}

Vpogled v stanje na področju ocenjevanja znanja pri tujih jezikih stroke na terciarni ravni v Sloveniji smo skušali pridobiti z anketo med učitelji tujih jezikov stroke na terciarni stopnji. Pri tem nas je zanimalo samo končno (sumativno) preverjanje ter tisto, ki je, tudi če se izvaja med semestrom (torej formativno), obvezni del končne ocene pri predmetu tuji jezik stroke.

\subsection{Cilji raziskave}

V teoretičnem delu smo podali kratek pregled obravnavane tematike in opozorili na nekatera dejstva in izzive pri ocenjevanju znanja pri jeziku stroke nasploh in posebej v terciarnem izobraževanju. Ožji cilj raziskave je dobiti vpogled v prakso ocenjevanja znanja pri tujih jezikih stroke na terciarnih ustanovah v Sloveniji. Širši (in dolgoročni) cilj pa je ozaveščanje o izzivih pri ocenjevanju znanja, s katerimi se v današnjem času soočamo učitelji tujih jezikov stroke v visokošolskem izobraževanju, saj, kot pravi Grotjahn (2000: 5) »je pričakovati, da bodo znanja na področju merjenja in presoje tujejezikovnih zmožnosti v prihodnje v Evropi spadala med osrednje karakteristike kvalificiranosti vsakega učitelja tujega jezika«.

\subsection{Metodologija}

\subsubsection{Vzorec}

K sodelovanju smo povabili 36 učiteljev tujega jezika stroke, katerih kontaktne podatke smo uspeli pridobiti. Natančnega števila učiteljev v času raziskave nismo imeli, kot osnovo smo vzeli takratni seznam učiteljev tujega jezika stroke pri Slovenskem društvu učiteljev tujega strokovnega jezika (SDUTSJ), na katerem je bilo 65 učiteljev tujega jezika stroke, na vseh štirih univerzah in zasebnih visokošolskih ustanovah. ${ }^{8}$ Ti predstavljajo osnovno množico.

8 Leta 2008, so Djurićeva, Godnič Vičičeva in Jurkovićeva delale raziskavo med učitelji tujega jezika stroke in nagovorile 94 učiteljev na treh univerzah v Sloveniji (četrta takrat še ni bila ustanovljena). Primerjava z današnjim stanjem jasno kaže na velik upad števila učiteljev tujega jezika stroke. 


\subsubsection{Instrumenti}

Podatke smo zbirali s pomočjo spletnega vprašalnika $1 \mathrm{ka}$, za katerega smo se odločili zaradi njegove dostopnosti in ekonomičnosti. Sestavili smo vprašalnik, ki je obsegal tri sklope vprašanj: prvi sklop (3 vprašanja) se je nanašal na formalno ureditev ocenjevanja znanja, drugi sklop ( 8 vprašanj) se je nanašal na vsebinsko in izvedbeno plat ocenjevanja, $\mathrm{v}$ tretjem sklopu (2 vprašanji) pa smo spraševali po demografskih podatkih. Na koncu smo dali anketirancem z odprtim vprašanjem možnost, da podajo svoje komentarje.

Zbirali smo podatke objektivnega in subjektivnega tipa in za to uporabili vprašanja zaprtega (10 vprašanj), kombiniranega ( 1 vprašanje) in odprtega tipa (2 vprašanji) ter petstopenjsko Likertovo lestvico stališč (1 vprašanje).

Vprašalnik sledi zahtevam za sestavo kvalitetnega vprašalnika. Vsebinsko veljavnost smo zagotovili tako, da je vprašalnik pregledala strokovnjakinja za didaktiko nemškega jezika in opravila racionalno presojo. Objektivnost, to je izključitev subjektivnih vplivov anketarja (Sagadin, 1993), zagotavlja zbiranje podatkov preko spleta. Uporabili smo tudi pretežno vprašanja zaprtega tipa, ki veljajo za bolj objektivna.

\subsubsection{Postopek}

Na elektronske naslove učiteljev tujega jezika stroke smo v januarju 2016 poslali vabilo $\mathrm{k}$ izpolnjevanju ankete $\mathrm{s}$ povezavo do nje. Ta datum smo izbrali zato, ker je $\mathrm{v}$ tem času izpitno obdobje in smo domnevali, da bodo učitelji občutljivejši za temo raziskave. V vabilu smo jih seznanili z namenom raziskave in jim zagotovili anonimnost. Navedli smo tudi naše kontaktne podatke za morebitna dodatna pojasnila. Na prvo vabilo se je odzvalo 14 učiteljev, zato smo po 14-ih dneh vabilo ponovili, odzvalo se je še osem učiteljev. Anketo smo zaključili po enem mesecu.

\section{REZULTATI IN INTERPRETACIJA}

\subsection{Podatki o vzorcu}

Anketo je v celoti izpolnilo 22 učiteljev, od tega 21 žensk in 1 moški, kar predstavlja (61 \% vzorca oziroma dobrih $33 \%$ osnovne množice). Največ anketirancev je iz starostne skupine 41-60 let (18 ali 82 \%), ostali (4 oziroma 18 \%) so iz starostne skupine 21-40 let, kar kaže na to, da na slovenskih visokošolskih ustanovah prevladujejo starejši učitelji, na podlagi česar lahko sklepamo, da imajo dolgoletne izkušnje pri poučevanju tujega jezika. Obenem ta podatek kaže na manj razveseljivo dejstvo, namreč, da je zelo malo mlajših učiteljev tujega jezika stroke na terciarni ravni, kar pa ne velja samo za učitelje tujega jezika stroke. Podatek se namreč ujema z ugotovitvami Eurydice (2017), po katerih spada Slovenija med države z najnižjim deležem učiteljev na terciarni ravni, starih pod 35 let. 


\subsection{Praksa ocenjevanja znanja}

V prvem delu vprašalnika so nas zanimali okvirni pogoji v zvezi z ocenjevanjem znanja.

V skladu s pričakovanji je odločanje o načinih ocenjevanja v celoti v domeni učiteljev tujih jezikov stroke (torej brez poseganja institucije), bodisi, da učitelji odločajo sami ali v okviru vsakokratne organizacijske oblike, npr. katedre. ${ }^{9}$ Pri tem je treba upoštevati, da je precej visokošolskih ustanov, ki imajo v študijskem programu samo en tuji jezik in tudi samo enega zaposlenega učitelja, zato je delež tistih, ki so popolnoma samostojni odločevalci, višji.

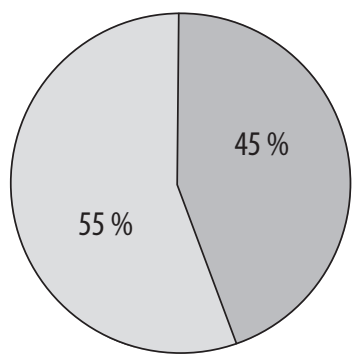

1 (odločamo v okviru katedre/ ali druge organizacijske enote za vse jezike enotno)

2 (odločam popolnoma samostojno)

Graf 1: Odločanje o postopkih ocenjevanja znanja pri predmetu

Na vprašanje o oblikah ocenjevanja znanja je le $5 \%$ vprašanih učiteljev odgovorilo, da uporabljajo samo pisni izpit, tretjina jih izvaja pisni in ustni izpit, največ, $(62 \%)$ anketirancev pa kombinira različne oblike ocenjevanja, kar lahko ocenimo kot pozitivno in $\mathrm{v}$ skladu s sodobnimi teoretičnimi smernicami. S kombinacijo več oblik ocenjevanja kompenziramo slabosti posameznih oblik, obenem pa se tudi bolj približamo študentovim potrebam, njihovim preferencam in kognitivnim ali osebnim stilom (Dimić in Stručić, 2008; Mauranen, 2012).

Ob tem je treba dodati, da je po uvedbi bolonjskega sistema študija na večini programov prišlo do prevetritve in posodobitve programov in s tem tudi do uvedbe novih oblik ocenjevanja znanja (Perović, Ignjačević in Svetlin Gvardjančič, 2005; Ribairo Pereira in Assunção Flores, 2016). Deloma lahko to odprtost pripišemo tudi starostni strukturi anketirancev. Raziskave na različnih stopnjah izobraževanja namreč kažejo, da so starejši in bolj izkušeni učitelji bolj naklonjeni uporabi raznolikih oblik ocenjevanja znanja (Bol, Stephenson, O`Connel in Nunnery, 1998; Žveglič Mihelič, 2017), med učenci/študenti pa so manj priljubljene, kot bi pričakovali (Vrkić Dimić in Stručić, 2008; Svetlin Gvardjančič, 2017)

9 Na nekaterih fakultetah učitelji tujih jezikov nimajo lastne katedre, ampak so vključeni v druge. 


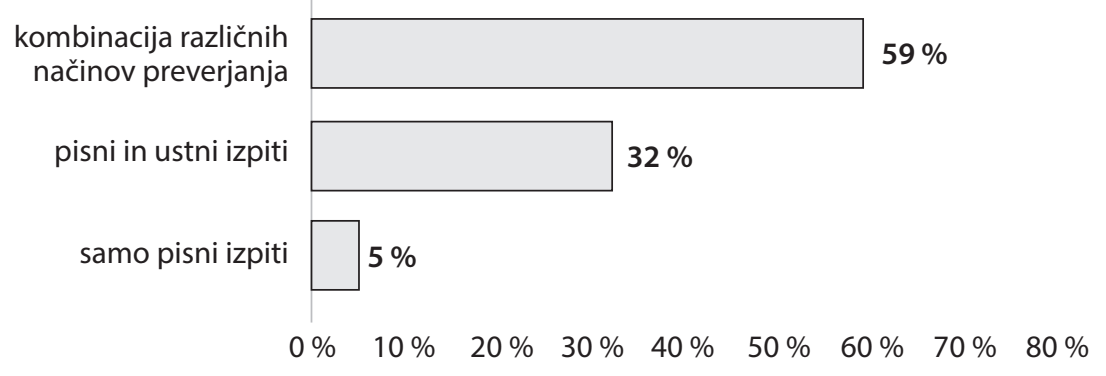

Graf 2: Oblike ocenjevanja znanja (sumativno ocenjevanje)

Med drugimi načini ocenjevanja znanja, ki jih učitelji uporabljajo poleg pisnega in ustnega izpita in so vključeni v končno oceno pri predmetu, močno izstopajo predstavitve študentov, ki jih uporablja $82 \%$ anketirancev, ostale oblike (kolokviji, igre vlog, projekti in seminarska dela) pa uporablja med dobro petino in slabo tretjino vprašanih učiteljev. Najmanj učitelji uporabljajo projekte, kar najbrž lahko pripišemo njihovi precejšnji časovni zahtevnosti. Seveda pa obstajajo tudi razlike med jeziki posameznih strok in njihovimi specifičnimi zahtevami glede jezikovnih znanj, čemur sledijo cilji pouka in končno tudi oblike ocenjevanja znanja. Zato je na primer na družboslovnih študijih več seminarskih nalog, medtem ko na tehniških študijih prevladujejo razne projektne naloge, poročila in podobno (Marentič Požarnik in Peklaj, 2002).

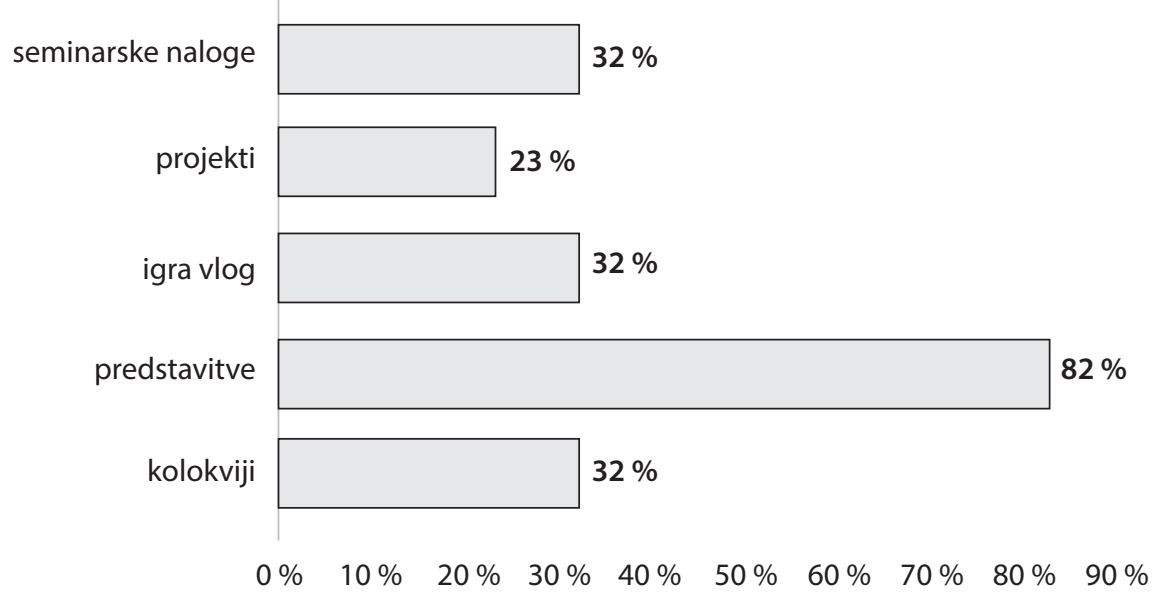

Graf 3: Ostali načini pridobivanja ocen 
V nadaljevanju smo želeli izvedeti podrobnosti o najpogostejših oblikah ocenjevanja znanja. Najprej nas je zanimalo pripravljanje pisnih izpitov. 17 učiteljev (77 \%) je navedlo, da jih pripravljajo povsem samostojno, slaba četrtina (23\%) pa jih pripravlja skupaj s kolegi in so izpiti tako enotni za posamezen jezik in/ali program. Rezultat je podoben kot pri vprašanju o odločanju o oblikah ocenjevanja, le da je samostojnost učitelja tu še nekoliko bolj izrazita. Seveda tudi tu velja upoštevati, da je na marsikateri visokošolski ustanovi za določen jezik zaposlen samo en učitelj.

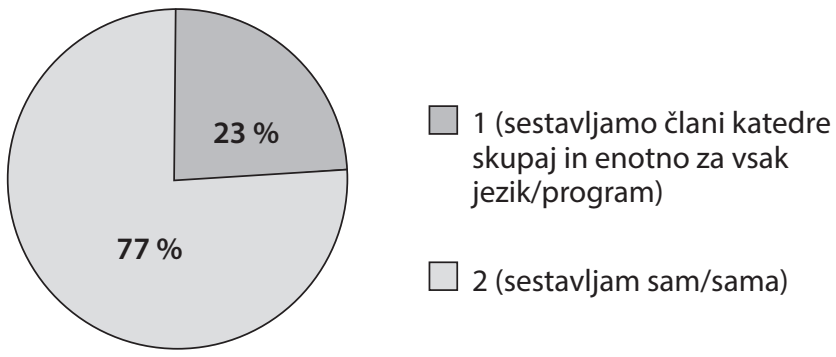

Graf 4: Priprava pisnih izpitov

Tudi pri naslednjem vprašanju, po čem se učitelji zgledujejo pri pripravi pisnih izpitov, se je izkazalo, da so zelo samostojni. Štiri petine (81 \%) učiteljev teste oblikuje po lastni presoji, $19 \%$ pa se jih pri tem zgleduje po razpoložljivih primerih standardiziranih testov (ki so na primer dostopni na spletu). To je pričakovano, saj je za teste v visokošolskem izobraževanju značilno, da so zelo pogosto koncipirani tako rekoč ,po meri‘ za bolj ali manj ozko specializirano ciljno skupino študentov in podobno, kot velja za gradiva za pouk, tudi ni testov, ki bi bili pripravljeni za posamezno stroko. Če pa ti za nekatere bolj izpostavljene stroke že obstajajo (na primer poslovni jezik, jezik tehnike, zdravstva), so, enako kot tudi učbeniki, namenjeni drugi ciljni skupini, namreč zaposlenim, ki pa se kot ciljna skupina razlikujejo od študentov.

po vzoru razpoložljivih standardiziranih testov (npr. vzorci testov dostopni na spletu)

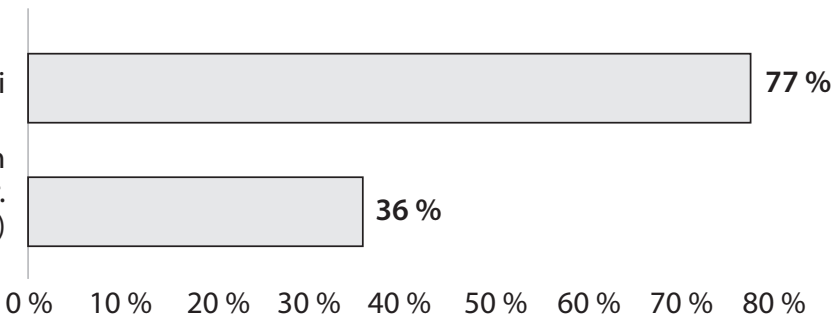


Glede ocenjevanja štirih spretnosti izstopa le majhen delež preverjanja slušnega razumevanja. Razlog za to je običajno predvsem tehnične narave, saj zlasti na programih z veliko študenti različnih letnikov in programov, ki opravljajo izpit naenkrat, to praktično ni izvedljivo. Ostale tri spretnosti, torej bralno razumevanje ter pisno in govorno sporočanje, so zastopani dokaj enakovredno, nekoliko izstopa le pisno sporočanje.

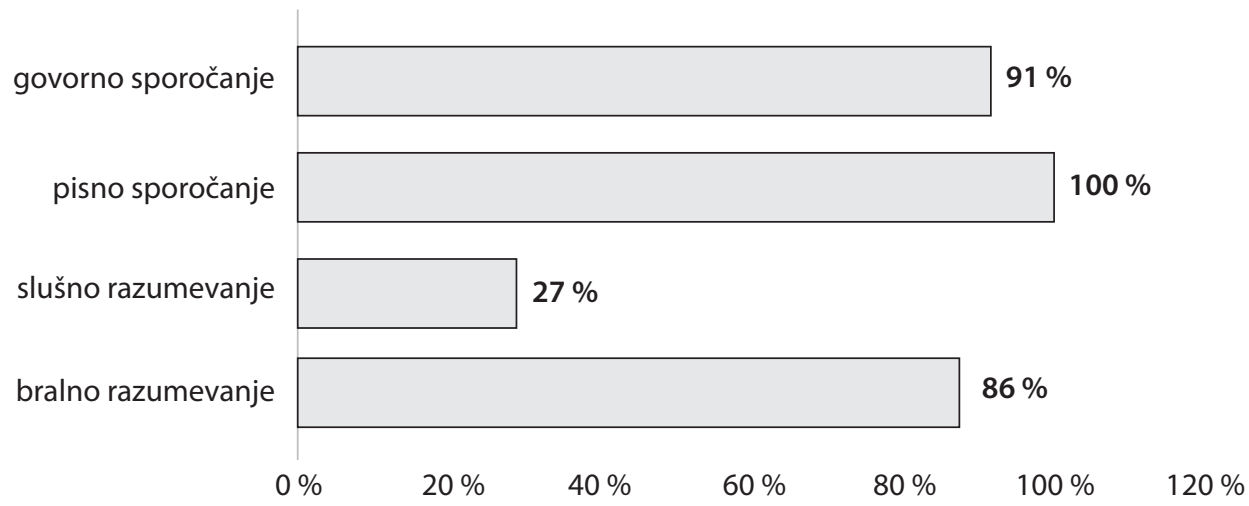

Graf 6: Ocenjevanje spretnosti pri pisnem izpitu

Pri vsebini je največ pozornosti namenjene strokovnemu besedišču, slovnica in strokovne vsebine ${ }^{10}$ so zastopani v približno enakem deležu. To ustreza teoretičnim načelom, ki so dolgo veljala (in marsikje še veljajo) ${ }^{11}$ za pouk tujega jezika stroke in po katerih je ravno osredinjenost na terminologijo tisto, kar ločuje pouk tujega jezika stroke od pouka splošnega tujega jezika (Fluck, 1998, Nitu, 2008)), medtem ko se slovnica ne obravnava sistematično in progresivno, marveč le selektivno.

vsebine vezane na stroko, katere jezik predavamo

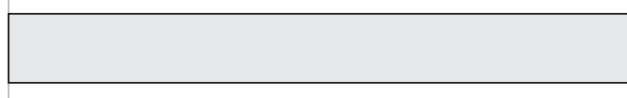

$82 \%$

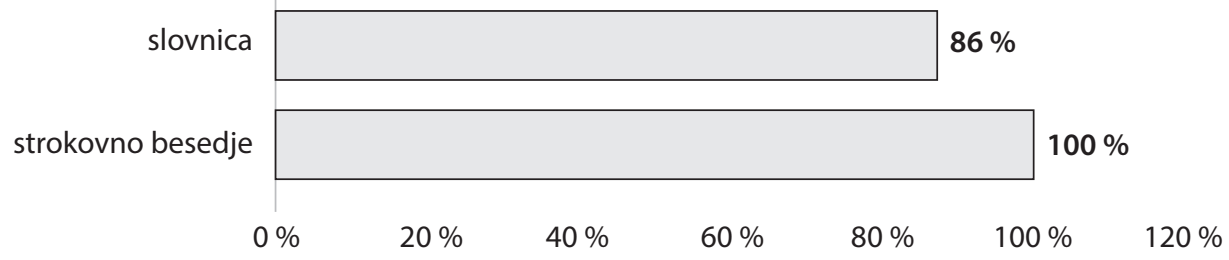

Graf 7: Vsebinski poudarki

10 Pod 'strokovne vsebine' spadajo tako pri jeziku ekonomije vsebine iz ekonomske znanosti, na primer pravno organizacijske oblike podjetij, bančništvo, finance in podobno.

11 Na primer na Pravni fakulteti PF obstaja predmet pravna terminologija v nemškem jeziku. 
Odgovori na vprašanje, kakšne tipe nalog učitelji vključujejo v pisne izpite, kažejo, da je težišče razločno na esejskih nalogah (73\%) in na nalogah objektivnega tipa, kamor spadajo vprašanja odprtega tipa. V našem primeru so to naloge dopolnjevanja (91 \%) in naloge s kratkimi odgovori (68 \%), za katere Marentič Požarnikova in Peklajeva, 2002) sicer menita, da je pri njih ocenjevanje lahko bolj subjektivno, glede nivojev znanja pa sežejo največ do razumevanja.

Pri odgovorih na vprašanje, kakšne tipe nalog učitelji vključujejo v pisne izpite, lahko pozitivno ocenimo visok odstotek (91 \%) nalog odprtega tipa, to so naloge dopolnjevanja in naloge s kratkimi odgovori, pa tudi širših odprtih vprašanj in kratkih odgovorov, s katerimi lahko merimo višje nivoje znanja (Marentič Požarnik in Peklaj, prav tam) ter na drugi strani opazno nižji delež nalog povezovanja (41\%), urejanja in alternativnega tipa s po $36 \%$, nekaj več je spet nalog alternativnega tipa (59\%). Slednje sicer terjajo več časa za pripravo, omogočajo pa bolj objektivno ocenjevanje in so bolj ekonomične glede popravljanja. Sicer je opazno, da pri učiteljih kriterij ekonomičnosti ni v ospredju, razlog je morda tudi v tem, da vsaj nekateri od njih in pri nekaterih manj zastopanih jezikih nimajo tako velikega števila študentov.

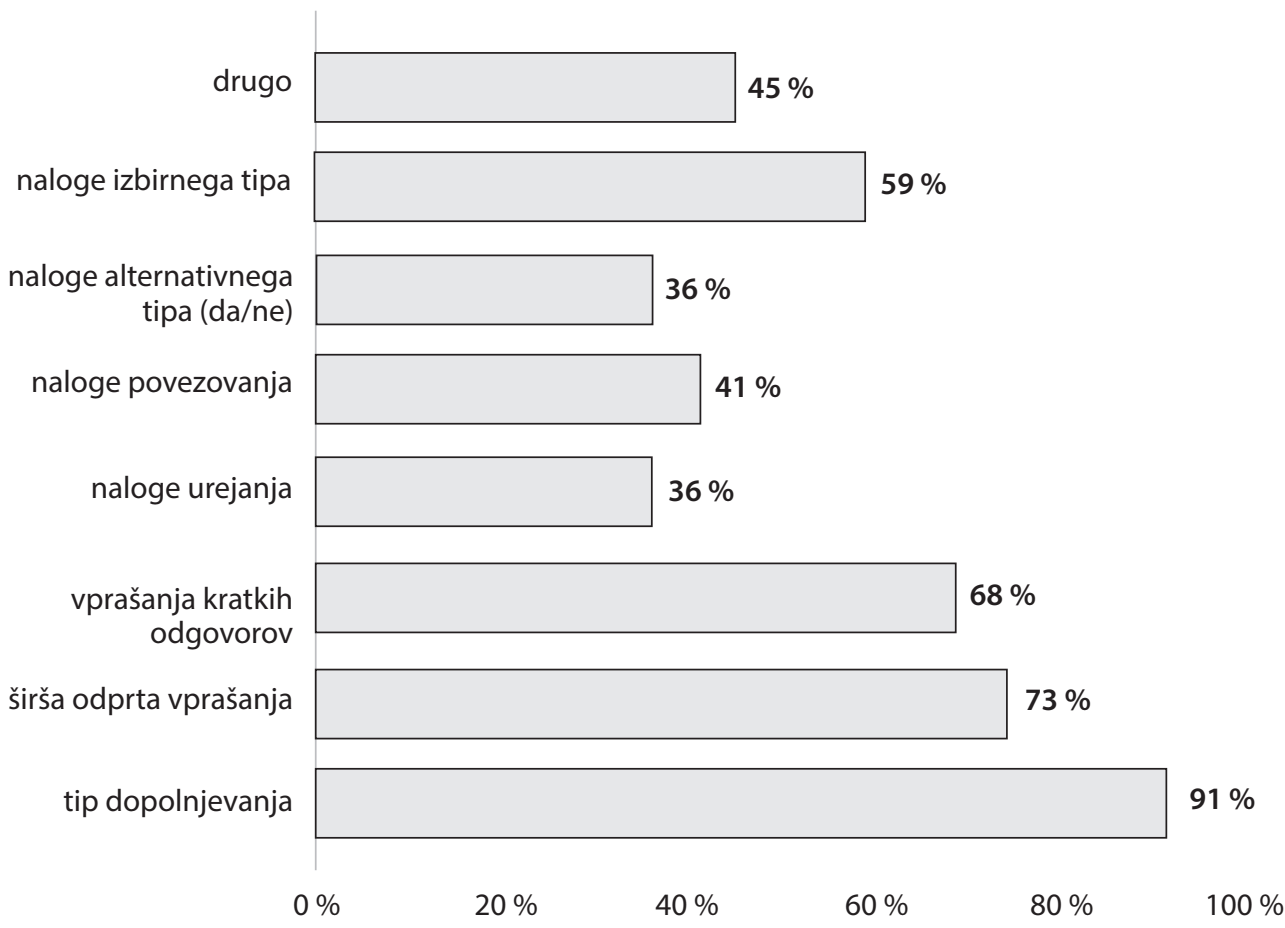


Sicer pa so učitelji pri vprašanju, katere druge tipe nalog, poleg zgoraj naštetih, še vključujejo v svoje teste, navedli:

\begin{tabular}{|c|}
\hline Drugo \\
\hline spis \\
\hline prevodi poslovnih pisem \\
\hline pisanje povzetkov \\
\hline opisi grafov, tabel \\
\hline argumentiranje \\
\hline korespondenca oz. kratko poročilo na dano temo \\
\hline pisanje sestavkov \\
\hline
\end{tabular}

Učitelji so odgovarjali tudi na odprto vprašanje o trajanju in vsebinah ustnega preverjanja. Odgovori kažejo, da je trajanje zelo različno, od 5 do 50 minut, ali to pomeni tudi različno težo ustnega izpita v končni oceni, učitelji niso navedli. Nekateri učitelji izvajajo izpite v parih ali v skupinah, drugi individualno. Da bi prikazali raznolikost vsebin, navajamo najpogostejše odgovore učiteljev:

\begin{tabular}{|c|}
\hline odgovor na 2 vprašanji iz predelane snovi \\
\hline obravnavane strokovne teme \\
\hline kratko strokovno besedilo, razumevanje celote, posameznih izrazov \\
\hline predstavitev po izbiri študenta \\
\hline diskusija na teme iz lekcij \\
\hline igra vlog \\
\hline small talk in predstavitev študenta ter njegove mini raziskovalne naloge \\
\hline študent predstavi knjigo, ki jo je prebral \\
\hline igranje vlog, opis grafike, argumentiranje (predstavitev dveh konceptov, \\
ponudb in odločitev za enega) \\
\hline pogovor ob prebranem članku in eni obravnavani enoti \\
\hline \begin{tabular}{c} 
komentar in izmenjava mnenj na osnovi naključno izbranega vprašanja \\
\hline študent izbere 2 tematski vprašanji in se nanju pripravi. V strukturiranem cca. \\
enominutnem monologu uporabi ključno strokovno besedišče
\end{tabular} \\
\hline
\end{tabular}

Kot je videti, pri ustnih izpitih prevladujejo teme, ki so študentom blizu in so jih obravnavali pri pouku. Poudarek je na uporabi strokovnega besedišča in značilnih komunikacijskih vzorcev za posamezni jezik stroke. To je na eni strani prijazno do študentov, ki se lahko vnaprej pripravijo, na drugi strani pa gre to na račun manjše spontanosti in nepredvidljivosti, ki bi bila verjetno boljša priprava na komunikacijo v realnem življenju 
oziroma bi napovedna veljavnost bila večja. Tako bi se izognili tudi učenju na pamet. Drugo dejstvo, ki izhaja iz takšne raznolikosti, pa je različna zahtevnost ustnega izpita (tudi znotraj iste ustanove), ki lahko postavi pod vprašaj enakopravnost študentov, glede na to, pri katerem učitelju opravljajo ustni izpit ${ }^{12}$.

Med alternativnimi načini ocenjevanja znanja močno prevladujejo seminarske naloge s $67 \%$, sledi ocenjevanje praktičnega izvajanja z $38 \%$, ter kolegialno ocenjevanje (ang. peer assessment) in ocenjevanje na osnovi portfelja s po $33 \%$. Izpite »odprtih knjig« uporablja samo eden od anketiranih učiteljev. Iz odgovorov lahko razberemo, da je še vedno najpogostejša uporaba najbolj »klasične« oblike, to pa so seminarske naloge. Pozitivno lahko ocenimo delež ocenjevanja na osnovi portfelja, ki med raziskovalci (Douglas, 2000; O‘Sullivan, 2012) velja za posebej primerno obliko za ocenjevanje znanja pri tujem jeziku stroke, ker lahko na ta način v ocenjevanje vključimo zelo raznolike ciljne situacije. Samoocenjevanje in kolegialno ocenjevanje si le počasi utirata pot v pedagoško prakso. Sklepali bi lahko, da so razlog temu učitelji, ki želijo ostati izključna instanca, ko gre za ocenjevanje, vendar pa nekatere raziskave za različne ravni izobraževanja kažejo, da ti dve obliki tudi med učenci in študenti nista posebej priljubljeni (Vrkić Dimić in Stručić, 2008; Goršak in Pižorn, 2010).

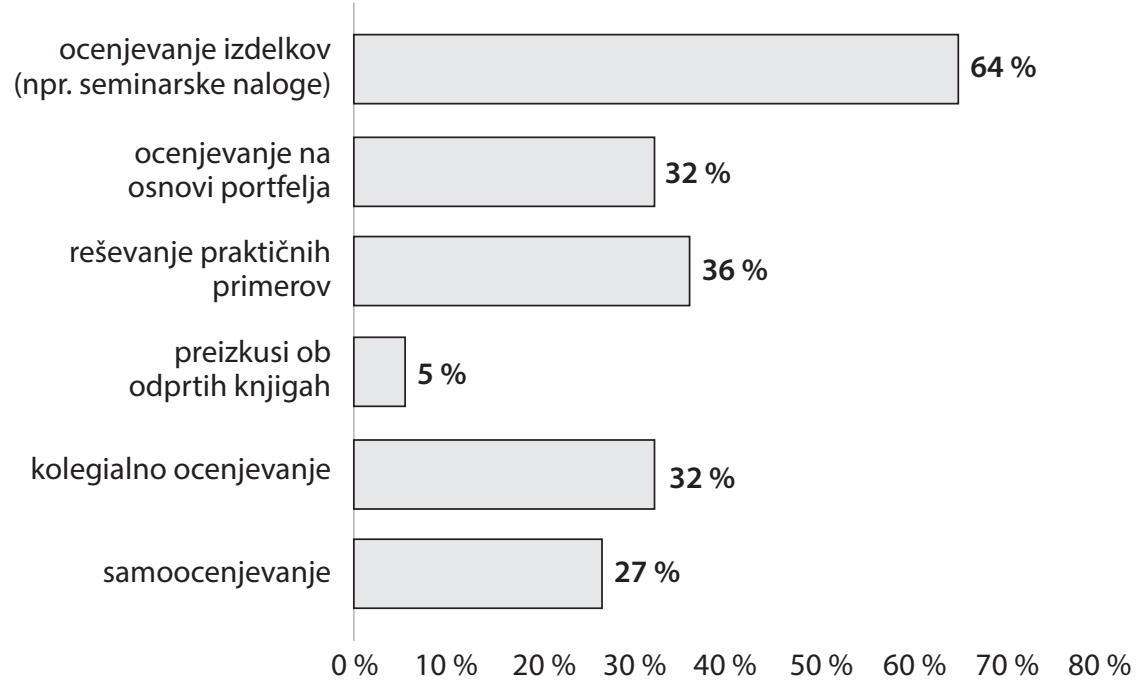

Graf 9: Uporaba alternativnih oblik ocenjevanja znanja

Končno smo želeli od učiteljev izvedeti njihova mnenja o nekaterih načelnih vprašanjih v povezavi z ocenjevanjem.

12 Analiza komentarjev študentov v študentskih anketah na Ekonomski fakulteti UL je pokazala na precejšno kritičnost študentov zaradi prevelikega razkoraka pri ustnih izpitih med posameznimi učitelji istega tujega jezika (Svetlin Gvardjančič, 2017). 
Največje strinjanje (55 \% se jih popolnoma strinja in $45 \%$ se jih strinja) so učitelji izrazili s trditvijo, da bi bila potrebna izmenjava izkušenj in dobrih praks med učitelji tujih jezikov stroke.

Zanimivo je, da je na drugem mestu po strinjanju trditev, da je najbolje, da učitelj izpite pripravi samostojno. Tako meni $54 \%$ anketirancev ( $27 \%$ se jih popolnoma strinja, $27 \%$ se jih strinja), $27 \%$ se niti strinja niti ne strinja. To si lahko razlagamo v smislu, kot da jim to ne predstavlja problema ali pa, da so morda manj naklonjeni timskemu delu. Seveda ob tem ne gre pozabiti na že omenjeno dejstvo, da je znatno število učiteljev takšnih, ki edini (celo na ravni države!) poučujejo tuji jezik določene stroke. Najbrž bi v ta kontekst lahko umestili tudi relativno medlo zanimanje za enotne standarde, s trditvijo se nobeden od učiteljev ne strinja popolnoma, strinja se $45 \%$ vprašanih, $20 \%$ je neopredeljenih, medtem ko se jih četrtina ne strinja, desetina pa se jih sploh ne strinja.

Več kot polovica anketirancev se tudi strinja, da učitelji tujih jezikov stroke potrebujejo dodatno izobraževanje za pripravo testov za jezik stroke. Pri zadnjih dveh trditvah, torej, da je področje ocenjevanja znanja v literaturi zadostno teoretično obravnavano, in o pogrešanju enotnih kompetenčnih standardov na področju tujih jezikov stroke, prevladujejo odgovori niti/niti, kar si morda lahko razlagamo kot neodločnost, najbrž pa gre razlog za to iskati zlasti v tem, da učitelji manj poznajo literaturo s tega področja in so o tem tudi teoretično manj poučeni. Če primerjamo to z vprašanjem o izmenjavi izkušenj, vidimo, da so učitelji zainteresirani za bolj praktično usmerjeno dodatno izobraževanje, kar se ujema tudi z nekaterimi raziskavami s tega področja (na primer Huhta, Hirvalä in Banerjee, 2005, v Fulcher, 2012) ki so pokazale, da učitelje bolj zanimajo praksa, morda osnovna statistika, manj pa zapletena statistična vprašanja (McNamara, 2009), kar nenazadnje glede na njihovo humanistično ozadje tudi ne preseneča.

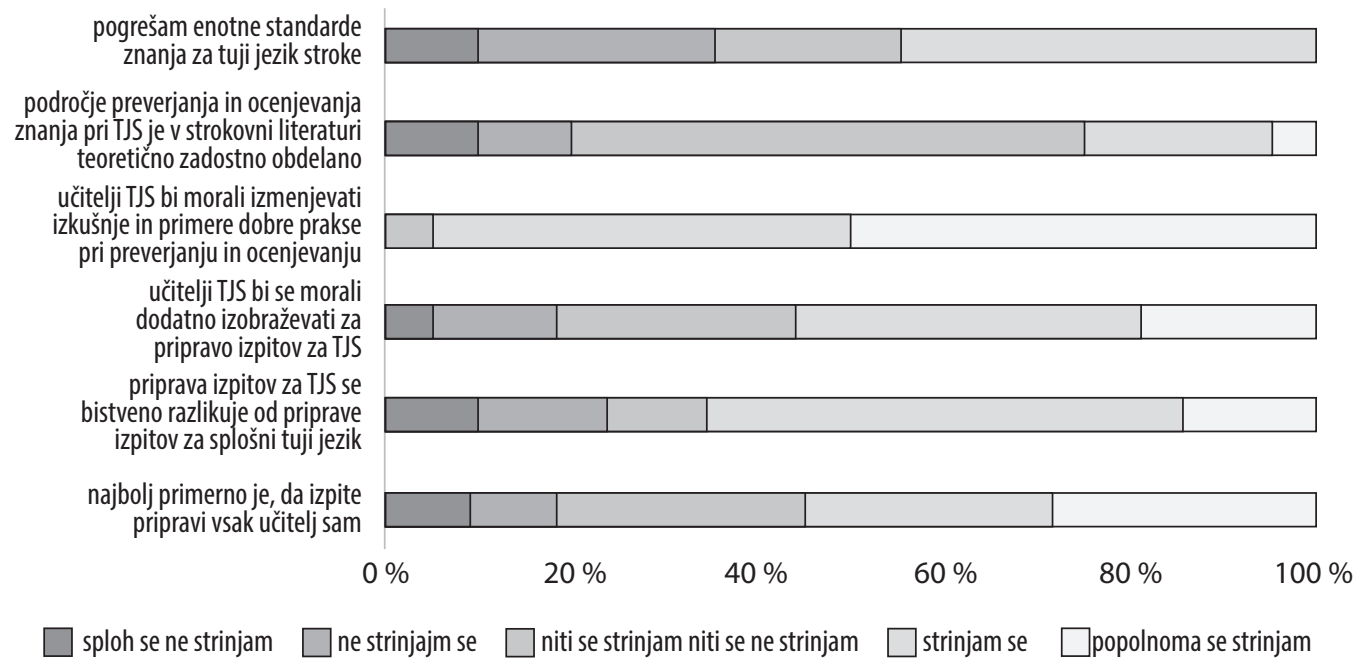

Graf 10: Mnenja učiteljev o nekaterih vidikih ocenjevanja znanja 
Zanimanje za ocenjevanje znanja se je $\mathrm{v}$ zadnjih desetletjih povečalo, kar je posledica spoznanja, da ocenjevanje znanja ni zgolj cilj, ampak sopotnik na poti k znanju s tem, ko v veliki meri določa učiteljeve pristope pri poučevanju in spremlja učenca/študenta pri njegovem usvajanju znanja, saj mu daje smernice za učenje. Učitelja pa ocenjevanje znanja spremlja tudi na njegovi poti nazaj, na začetek, k novim učencem/študentom, ker $\mathrm{mu}$ daje povratno informacijo in smernice za ravnanje v prihodnje.

Ocenjevanje znanja pri tujih jezikih stroke zaznamuje na eni strani institucionalni okvir, to je visokošolska ustanova s svojimi pravili, na drugi strani stroka, katere jezik predava učitelj in ki mora biti vključena $v$ vse faze njegovega pedagoškega dela: pri analizi potreb, določanju ciljev, opredelitvi standardov in končno pri ocenjevanju znanja. Tretji dejavnik pa so študenti, kot specifična ciljna skupina, ki še nima tako jasno definiranih predstav o svojih jezikovnih potrebah kot na primer odrasli zaposleni, obenem pa je v današnji izrazito kompetitivni družbi na vsakem koraku odvisna od različnih ocen in/ali ocenjevanj.

Rezultati spletne ankete so potrdili predvidevanja o tem, da je pri ocenjevanju znanja na področju tujih jezikov stroke učitelj večinoma avtonomen, kar samo po sebi ni problematično in, kot kažejo odgovori, to učiteljev ne obremenjuje. Izkazalo se je, da učitelji dokaj enotno uporabljajo različne oblike pridobivanja končnih ocen pri svojih predmetih in $\mathrm{v}$ tem ne odstopajo od običajnih praks. Poudarjeno individualni karakter ocenjevanja znanja pa se je zelo jasno pokazal pri praksi ustnih izpitov, kjer komaj lahko najdemo skupne imenovalce. To sproža tudi vprašanje zahtevnosti in posledično primerljivosti končnih ocen, kar je pri tako raznolikih praksah lahko vprašljivo tudi znotraj ene in iste visokošolske ustanove in/ali predmeta. Ravno zato gre slediti mnenju učiteljev, da bi bilo potrebno več sodelovanja in izmenjave dobrih praks med učitelji tujega jezika stroke v slovenskem visokošolskem prostoru. S pričujočo raziskavo smo želeli narediti korak v tej smeri.

\section{LITERATURA}

BOL, Linda/STEPHENSON Patricia L./O‘CONNEL, Ann A./NUNNERY, John A. (1998) Influence

of Experience, Grade Level, and Subject Area on Teacher's Assessment Practices. The Journal of Educational Research 91, 323-330.

BRUNFAUT, Tineke (2014) Language for Specific Purpose: Current and Future Issues. Language Assessment Quarterly 11, 216-225.

CHANG, Chiung-Wen (2014) Teachers' beliefs and practices about ESP assessment: a phnemographic study. The Journal of Teaching Englisch for Specific and Academic Purposes 2, 625-645.

DAVIES, Alan (2001) The logic of testing Languages for Specific Purposes. Language Testing 18, 133-147. 
DJURIĆ, Melita (2008) Dealing with Situations of Positive and Negative Washback. Scripta Manent 4, 14-27.

DOUGLAS, Dan (2000) Assessing Languages for Specific Purposes. Cambridge: Cambridge University Press.

DOUGLAS, Dan (2001b) Three problems in testing language for specific purposes: Authenticity, specificity and inseparability. V R. Unido (ur.), Experimenting with uncertainty - essays in honour of Alan Davies. Cambridge: Cambridge University Press, 45-52.

FLUCK, Hans-R. (1998) Bedarf, Ziele und Gegenstände fachsprachlicher Ausbildung. V L. Hoffmann, H. Kalverkämper in H. E. Wiegrand (ur): Fachsprachen: Ein internationales Handbuch zur Fachsprachenforschung und Terminologiewissenschaft. Berlin: de Gruyter, 944-954.

FULCHER, Glenn (2012) Assessment literacy for the language classroom. Language Assessment Quarterly 9, 1-17.

GORŠAK, Karmen/Karmen PIŽORN (2010) Prednosti in pomanjkljivosti vrstniškega ocenjevanja: umestitev vrstniškega ocenjevanja v pouk tujih jezikov v gimnaziji. Vestnik za tuje jezike 2 193-205.

GROTJAHN, Rüdiger (2002) Leistungsmessung und Leistungsbeurteilung. Postrgraduiertenstudium Deutsch als Fremdsprache. Patras: Hellenic Open University. 18. januar 2017. http://herder.philol.uni-leipzig.de/temp/lehrende/tschirner/testen/grundlag.pdf

HUTCHINSON, Tom/Alan WATERS (1987) English for Specific Purposes: A Learning Centred Approach. Cambridge: Cambridge University Press.

JACOBY, Sally/Tim McNAMARA (1999) Locating Competence. English for Specific Purposes 18, 213-241.

MARENTIČ POŽARNIK, Barica/Cirila PEKLAJ (2002) Preverjanje in ocenjevanje za uspešnejši študij. Ljubljana: Center za pedagoško izobraževanje Filozofske fakultete.

MAURANEN, Anna (1989) New Directions in LSP Testing at Finnish Universities [Washington, D.C.]: Distributed by ERIC Clearinghouse,

McNAMARA, Tim (2009) Principles of testing and assessment. V K. Knapp in B. Seidlhofer (ur.), Handbook of Foreign Language Communication and Learning. Berlin: Walter de Gruyter, 607-627.

McNAMARA, Tim/Kerry RYAN (2011) Fairness Versus Justice in Language Testing: The Place of English Literacy in the Australian Citizenship Test. Language Assessment Quarterly 8, 161-178.

NIŢU, Raluca (2008) Assessing Language for Specific Purposes. Referat predstavljen leta 2008 na konferenci Language and Literature. European Landmarks of Identity. Izvleček pridobljen dne 1.9.2014 s http://www.diacronia.ro/ro/indexing/details/A5665/pdf. OPRE, Dana (2015). Teacher's Conceptions of Assessment. Procedia - Social and Behavioral Sciences 209, 229-233. 
O‘SULLIVAN, Barry (2012). Assessment Issues in Language for Specific Purposes. The Modern Language Journal 96, 71-88.

RIBEIRO PEREIRA, Diana/Maria FLORES ASSUNÇÃO (2016) Conceptions and Practices of Assessment in Higher Education: Study of Portuguese University Teachers. Revista Iberoamericana de Evaluación Educativa, 9, 9-29.

SAGADIN, Janez (1993) Poglavja iz metodologije pedagoškega raziskovanja. Ljubljana: Zavod Republike Slovenije za šolstvo in šport.

SVETLIN GVARDJANČIČ, Polona (2017) Leistungsbeurteilung im Fachsprachenunterricht aus der Sicht der Studierenden. V: 16. Internationale Tagung der Deutschlehrerinnen und Deutschlehrer, Freiburg, Schweiz, 31.Juli - 4. August 2017. https://events. artefact-sa.ch/artefact/frontend/reg/absViewDocumentFE.csp?documentID=895.

TRATNIK, Alenka (2008) Key Issues in Testing English for Specific Purposes. Scripta Manent, 4, 3-13.

VRKIĆ DIMIĆ, Jasmina/Maja STRUČIĆ (2008). Mišljenja učenika o provođenju provjeravanja i ocjenjivanja u nastavnoj praksi. Zadar: Univerza v Zadru.

ZALIPYATSKIKH, Natalya (2017). Didaktik der technischen Fachkommunikation. Berlin: Frank \& Timme.

ZUPANC, Darko/Matevž BREN (2010) Inflacija pri internem ocenjevanju v Sloveniji. Sodobna pedagogika 3, 208-228.

\section{POVZETEK}

\section{Praksa ocenjevanja znanja pri tujem jeziku stroke v slovenskem visokošolskem prostoru}

Zanimanje za ocenjevanje znanja se je v zadnjih desetletjih povečalo, tako na področju terciarnega izobraževanja kot na področju tujih jezikov stroke. V teoretičnem delu smo osvetlili razloge za ta premik in opozorili na ključne teme, ki zanimajo raziskovalce na omenjenem področju. Z raziskavo smo opravili posnetek stanja pri ocenjevanju znanja tujega jezika stroke na visokošolskih ustanovah v Sloveniji. Rezultati potrjujejo osrednjo vlogo učitelja tujega jezika stroke pri vseh opravilih, ki zadevajo ocenjevanje znanja: odločanje o načinih, priprava testov in podelitev ocene. Praksa ocenjevanja znanja kaže na to, da učitelji v ocenjevanje znanja pozorno vključujejo teme, ki so relevantne za stroko, katere jezik predavajo, v izvedbenem delu pa sledijo trendom v pedagoški stroki, kar se odraža v uporabi različnih oblik ocenjevanja. Kljub temu, da se jim zdi primerno, da sami odločajo o ocenjevanju znanja, pa si želijo več sodelovanja in izmenjave izkušenj s kolegi.

Ključne besede: tuji jezik stroke, terciarno izobraževanje, praksa ocenjevanja znanja, alternativne oblike ocenjevanja znanja, učitelj tujega jezika stroke 


\section{ABSTRACT \\ Assessing Foreign Languages for Specific Purposes in Slovenian Higher Education}

In recent decades, interest in assessment has increased in relation to both tertiary education and languages for specific purposes (LSP). The theoretical part of this paper elucidates the reasons for this shift and draws attention to key topics of interest to researchers in this field. A study was conducted to determine current practice in LSP assessment at Slovenian higher-education institutions. Its findings confirm the central role of LSP teachers in all the tasks relating to grading students' proficiency: selecting the assessments methods, preparing tests, and assigning grades. Assessment practice indicates that teachers carefully include topics relevant to the individual discipline for the languages they teach and, as far as actual assessment is concerned, they follow current trends in education, which is reflected in the use of various forms of assessment. Even though they feel it is appropriate that they can make decisions on assessment themselves, they would prefer more cooperation and experience sharing with their colleagues.

Key words: foreign language for specific purposes, tertiary education, assessment practice, alternative forms of assessment, LSP teacher 